\title{
Overexpression of non-SMC condensin I complex subunit $G$ serves as a promising prognostic marker and therapeutic target for hepatocellular carcinoma
}

\author{
WANWEI LIU*, BO LIANG* , HONGLIANG LIU, YONG HUANG, XIANGBAO YIN, FAN ZHOU, \\ XIN YU, QIAN FENG, ENLIANG LI, ZHENHONG ZOU and LINQUAN WU
}

Department of General Surgery, The Second Affiliated Hospital, Nanchang University, Nanchang, Jiangxi 330006, P.R. China

Received July 6, 2016; Accepted July 12, 2017

DOI: $10.3892 /$ ijmm.2017.3079

\begin{abstract}
The non-SMC condensin I complex subunit G (NCAPG) that organizes the coiling topology of individual chromatids, represents an overexpressed antigen in various types of cancer, and also contributes to restructuring chromatin into rod-shaped mitotic chromosomes and ensuring the segregation of sister chromatid during cell division. In this study, we investigated the association between NCAPG expression and the biological behavior of hepatocellular carcinoma (HCC) to further explore the potential of NCAPG as a therapeutic target. The expression of NCAPG was detected in human HCC cell lines and tumor samples. The effects of NCAPG on the cell cycle, apoptosis and metastasis were investigated by various assays. NCAPG was found to be overexpressed in HCC compared with the adjacent normal tissue $(\mathrm{P}<0.001)$, and high levels of NCAPG expression were found to significantly correlate with recurrence, the time of recurrence, metastasis, differentiation and TNM stage. Furthermore, an elevated expression of NCAPG was associated with a poor overall survival $(\mathrm{P}<0.05)$. In addition, in vitro experiments further confirmed the ex vivo data; i.e., the knockdown of NCAPG expression reduced HCC cell viability, but induced apoptosis and arrested the cells at the $\mathrm{S}$ phase of the cell cycle. The knockdown of NCAPG expression also inhibited tumor cell migration and the cell invasive capacity in vitro. At the protein level, the knockdown of NCAPG expression upregulated Bax, cleaved caspase-3 and E-cadherin, but downregulated cyclin A1, CDK2, Bcl-2, N-cadherin and HOXB9 expression, suggesting that the knockdown of NCAPG expression suppressed tumor
\end{abstract}

Correspondence to: Professor Linquan Wu or Dr Zhenhong Zou, Department of General Surgery, The Second Affiliated Hospital, Nanchang University, 1 Minde Road, Nanchang, Jiangxi 330006, P.R. China

E-mail:wulqne@163.com

E-mail: 1025377834@qq.com

${ }^{*}$ Co-first authorship

Key words: non-SMC condensin I complex subunit G, hepatocellular carcinoma, cell-cycle arrest, apoptosis, metastasis cell epithelial-mesenchymal transition. On the whole, this study demonstrates that NCAPG plays an important role in the development and progression of HCC, and that it may be a novel therapeutic target for patients with HCC.

\section{Introduction}

Hepatocellular carcinoma (HCC) is one of the most prevalent malignancies, and it is the second cause of cancer-related mortality worldwide (1). Despite significant improvements in diagnosis and treatment techniques, the early recurrence and intrahepatic and distant organ metastasis rates following curative hepatectomy in patients with HCC remains generally high. Thus, recurrence and metastasis are a major obstacle which influence the survival time of patients with HCC (2). Therefore, in order to improve the survival rate of patients with HCC, it would be beneficial to identify novel biomarkers for diagnostic and prognostic targets.

Mitotic chromosome condensation is an essential cellular characteristic of all proliferative cells and is responsible for restructuring chromatin into rod-shaped mitotic chromosomes and ensuring the segregation of sister chromatids during cell division $(3,4)$. The condensin complexes were detected and purified from Xenopus egg extracts for the first time (5), which was considered to be a key factor in understanding the mitotic chromosome condensation to achieve mitosis-specific chromosome compaction and exact chromosome segregation (6). Existing research indicates that two types of condensin complexes are found in vertebrates, condensin I and II complexes, which both contain non-structural maintenance of chromosomes (non-SMC) regulatory subunits (6). The non-SMC subunits have been proposed to control the activity of ATP-dependent DNA supercoiling and chromosome segregation, and the depletion of any one of the subunits in condensin I or II can cause defective mitotic chromosome condensation (7-9).

Non-SMC condensin I complex subunit G (NCAPG), a mitosis-related chromosome condensation protein, is one of the non-SMC subunits that exists in the condensin I complex (10). As the counterpart of the Xenopus chromosome-associated polypeptide G (XCAP-G) gene, it was first purified from HeLa cell nuclear extracts (5). NCAPG is a polypeptide consisting 
of 1,015 amino acids with a relative molecular mass of $114.1 \mathrm{kDa}(5)$, and is encoded by the NY-MEL-3 gene located on human chromosome band 4p15.32 (11). Research has indicated that NCAPG is cell cycle-related $(11,12)$ and can influence the proliferation of HCC cells (13); however, the biological functions of NCAPG in HCC remain unknown. In the present study, we aimed to investigate the association between clinicopathological parameters and the NCAPG protein expression level in patients with HCC, and the effects of NCAPG on the cell cycle, apoptosis, invasion and migration.

\section{Materials and methods}

Patients and tissue samples. A total of $88 \mathrm{HCC}$ tissue specimens and paracancerous tissue specimens were provided by patients who underwent surgeries at the Second Affiliated Hospital of Nanchang University, Nanchang, China from 2012 to 2013. Based on the World Health Organization standard, the histological diagnosis and tumor differentiation grade of all the specimens were evaluated by the Department of Pathology of the Second Affiliated Hospital of Nanchang University. The patient's age, gender, tumor size, alpha-fetoprotein (AFP) levels and other clinicopathological factors were obtained from surgical and pathological records. Prior to specimen collection, no patients had received any treatments, including radiotherapy and chemotherapy. Fresh liver cancer tissue specimens and paracancerous tissue specimens were immediately placed in liquid nitrogen, and then stored at $-80^{\circ} \mathrm{C}$. In this study, ethics approval was provided by the Medical Ethics Committee of the Second Affiliated Hospital to Nanchang University, and written informed consent was obtained from all patients prior to obtaining the samples. This study was performed in accordance with the ethical standards of the Declaration of Helsinki.

Cell lines and culture. The normal control cell line, L02 (Cat. no.BNCC100012), and 5 humanHCC celllines [SMMC-7721 (Cat. no. BNCC100526), HepG2 (Cat. no. BNCC338070), MHCC-97H (Cat. no. BNCC337738), Hu7 (Cat. no. BNCC100280) and MHCC-LM3 (Cat. no. BNCC338460; all from BeNa Culture Collection, Beijing China)] were selected to conduct the assays, and the L02 cell line was selected as the normal control. These cell lines were cultured in high-glucose DMEM containing $10 \%$ fetal bovine serum (FBS), $100 \mathrm{U} / \mathrm{ml}$ penicillin and $100 \mu \mathrm{g} / \mathrm{ml}$ streptomycin at $37^{\circ} \mathrm{C}$ and in a humidified atmosphere of $5 \% \mathrm{CO}_{2}$.

Immunohistochemistry. A two-step immunohistochemical method (PV-9000; ZSGB-BIO Co., Ltd., Beijing, China) was adopted to perform the immunostaining. After being fixed in $10 \%$ neutral formalin solution, we embedded the HCC tissues in paraffin blocks and cut the tissue into 4-mm-thick paraffin sections for immunostaining. After being deparaffinized and hydrated, all the sections were added to $3 \% \mathrm{H}_{2} \mathrm{O}_{2}$ for $15 \mathrm{~min}$ to eliminate endogenous peroxidase and then repaired in a microwave oven at $130^{\circ} \mathrm{C}$ for $10 \mathrm{~min}$. Subsequently, the tissue sections were incubated with NCAPG mouse monoclonal antibody (1:200) (Abcam, Cambridge, UK) at $4^{\circ} \mathrm{C}$ overnight. Phosphate-buffered saline (PBS) was used to wash the sections 3 times at $5 \mathrm{~min}$ intervals. The secondary antibody biotinylated goat anti-mouse serum IgG (Cat. no. SPN-9002; PV-9000;
ZSGB-BIO Co., Ltd.) was added at $37^{\circ} \mathrm{C}$ for $30 \mathrm{~min}$, after using PBS to wash for 5 min 3 times; the diaminobenzidine and hematoxylin dyes were employed, and the sections were sealed with neutral resins. Two independent pathologists evaluated all of the sections' immunoreactivity blindly and randomly. The positive staining of NCAPG was located in the nucleus, adn thus the nuclear staining of the tumor cells was identified as positive immunostaining. The staining intensity and the percentage of tumor cells with positive staining was used to evaluate the results; the staining intensity was graded as follows: 0, no staining; 1+, mild staining; $2+$, moderate staining; or 3+, strong staining. The percentage of staining was scored as follows: 0 , no staining; $1,<10 \%$ staining; $2,10-40 \%$ staining; or $3,>40 \%$ staining. The overall staining index was then computed by multiplying these two scores to reach a value from 0 to 9 for each immunostained section and summarized and designated as follows: 0-1, negative NCAPG expression; or 2-9, positive expression.

Cell transfection and siRNA treatment. NCAPG siRNA and negative control siRNA were purchased from GenePharma Co. (Shanghai GenePharma Co., Ltd., Shanghai, China). The MHCC-LM3 and Hu7 cells were assigned to the blank group, control groups and NCAPG siRNA groups.Lipofectamine 2000 (Invitrogen Life Technologies, Carlsbad, CA, USA) was used to transiently transfect the cells with siRNA. Three different siRNA sequences were transfected into the cells in the NCAPG siRNA group, and the sequences were as follows: NCAPG_s1, GGAGUUCAUUCAUUACCUUTTAAGG UAAUGAAUGAACUCCTT; NCAPG_s2, GCUGAAA CAUUGCAGAAAUTTAUUUCUGCAAUGUUUCAGCTT; NCAPG_s3, GGACUAAUCAGGAAUGCUUTTAAGCA UUCCUGAUUAGUCCTT. The cells were seeded in 6-well plates and transfected with transfection mixture for $48 \mathrm{~h}$, and the transfected cells were then harvested and used in further assays.

Cell proliferation assay. Cell proliferation was detected using the Cell Counting kit-8 (CCK-8) assay. The HCC cells were seeded into 96 -well plates at a density of $1 \times 10^{4}$ cells/well and incubated for $24 \mathrm{~h}$ at $37^{\circ} \mathrm{C}$ in $5 \% \mathrm{CO}_{2}$. These wells were divided into 3 groups (NC, NCAPG siRNA-s1 and NCAPG siRNA-s2 groups) and each group occupied 5 replicate wells, and each treatment group was transfected with siRNA-NCAPG. After $0,24,48,72$ and $96 \mathrm{~h}$ of cultivation, $10 \mu \mathrm{l} \mathrm{CCK}-8$ reagent (CCK-8; Dojindo Laboratories, Kumamoto, Japan) were added to each well followed by cultured for $3 \mathrm{~h}$ at $37^{\circ} \mathrm{C}$ in $5 \% \mathrm{CO}_{2}$. The absorbance at $450 \mathrm{~nm}$ was measured using a microplate reader (Bio-Rad, Berkeley, CA, USA).

Measurement of cell apoptosis by flow cytometry. Cell apoptosis was examined by FACS analysis using the Annexin V-FITC/PI apoptosis detection kit from BD Biosciences (San Jose, CA, USA). Briefly, the cells subjected to the different treatments were harvested and washed twice in cold PBS, then gently re-suspended in $100 \mu \mathrm{l}$ binding buffer and added to a plastic $12 \times 75 \mathrm{~mm}$ test tube, followed by the addition of $5 \mu \mathrm{l}$ of Annexin V-FITC and $5 \mu \mathrm{l}$ of propidium iodide solution in the dark at $37^{\circ} \mathrm{C}$. Following incubation for $15 \mathrm{~min}, 400 \mu \mathrm{l}$ of $1 \mathrm{X}$ binding buffer were added to the cell suspension. The cells were examined by a BD FACScan flow cytometer (BD Biosciences) after $1 \mathrm{~h}$. 
Cell cycle analysis by flow cytometry. Cell cycle analysis was detected by FACS analysis. Briefly, the cells $\left(1 \times 10^{6}\right)$ were collected at $48 \mathrm{~h}$ by trypsinization after the various treatments, washed twice with cold PBS, resuspended and fixed in $1 \mathrm{ml}$ of cold $70 \%$ ethanol overnight at $4^{\circ} \mathrm{C}$. After washing once in cold PBS, the cells were re-suspended in $500 \mu \mathrm{l}$ of PI/RNase staining solution (Tianjin Sungene Biotech Co., Ltd., Tianjin, China) in the dark at room temperature for $30 \mathrm{~min}$. Subsequently, the cells were analyzed by BD FACScan flow cytometer (BD Biosciences) and CellQuest software.

Cell invasion and migration assays. Cell invasion was evaluated using Transwell inserts with $8 \mu \mathrm{m}$ pores (Corning, Inc., Corning, NY, USA). Briefly, $48 \mathrm{~h}$ after transfection, the NCAPG siRNA-treated cells and control groups cells were re-suspended in DMEM medium without serum and growth factor, and then $200 \mu \mathrm{l}$ cell suspension was seeded in the upper Transwell chambers. Subsequently, $500 \mu 1$ medium containing $20 \%$ FBS was added to the bottom of the chambers. The 24-well culture plate was incubated at $37^{\circ} \mathrm{C}$ in a humidified atmosphere containing $5 \% \mathrm{CO}_{2}$ for $48 \mathrm{~h}$. Cells remaining on the upper surface of the Transwell chambers were mechanically removed using a cotton swab, and then the underside of the Transwell chambers was fixed, washed and stained by hexamethyl pararosaniline. Five random fields on the lower surface of each Transwell chamber were counted. The migration assay procedures differed from the invasion assay, in that they were performed in the Transwell chambers that were not pre-coated with Matrix gel.

Western blot analysis. Western blot analysis was performed to detect the total protein expression of the treated cells $48 \mathrm{~h}$ after transfection. The cells were lysed in radioimmunoprecipitation assay (RIPA) buffer with $1 \%$ phenylmethanesulfonyl fluoride to extract the total protein. Protein concentrations were electrophoresed on an $8 \%$ sodium dodecyl sulfate-polyacrylamide gel and transferred onto polyvinylidene fluoride membranes, and the membranes were then incubated with anti-NCAPG (Cat. no. ab56382), anti-Bax (Cat. no. ab32503), anti-Bcl-2 (Cat. no. ab32124), cleaved caspase-3 (Cat. no. ab13847), anti-CDK2 (Cat. no. ab32147), cyclin A1 (Cat. no. ab53699), anti-HOXB9 (Cat. no. ab208920), anti- $\beta$-actin (Cat.no. ab8226), anti-N-cadherin (Cat. no. ab18203), anti-E-cadherin (Cat. no. ab1416) antibodies (all from Abcam) at $4^{\circ} \mathrm{C}$ overnight. Tris- $\mathrm{HCl}$ buffer solution + Tween-20 was used to wash the membranes 3 times per $10 \mathrm{~min}$. Subsequently, they were incubated with horseradish peroxidase-conjugated secondary antibody (Cat. nos. ab6789 and ab6721; 1:10,000; Abcam) for $1 \mathrm{~h}$ at room temperature, and signals were detected by enhanced chemiluminescent substrates (Millipore, Billerica, MA, USA).

Statistical analysis. SPSS 13.0 statistical software (SPSS, Inc., Chicago, IL, USA) was used for all statistical analyses. Wilcoxon's paired test was used to compare the expression of NCAPG in the HCC tissue specimens and paracancerous tissue specimens. Chi-square tests were used to examine possible correlations between NCAPG expression and clinicopathological characteristics. Overall survival was assessed using Kaplan-Meier curves, and the difference in overall survival was stratified by NCAPG expression and evaluated using the log-rank test. The Cox proportional hazards regression model was used to assess the hazard ratio and to identify factors that independently predicted overall survival. The in vitro data are expressed as the means \pm standard error and analyzed using one-way analysis of variance using factorial design to compare the growth curves of the different siRNA treatment groups. The P-value was based on the two-sided statistical analysis, and value of $\mathrm{P}<0.05$ was considered to indicate a statistically significant difference.

\section{Results}

NCAPG protein is highly expressed in HCC tissues compared with adjacent non-tumor tissues. We performed immunohistochemistry to investigate NCAPG protein expression levels in a total of $88 \mathrm{HCC}$ tissues and adjacent non-tumor tissues and found that NCAPG was expressed in the cell nuclei. However, the protein expression of NCAPG was at a low level in 7/88 (7.95\%) of the adjacent non-tumor tissues (Fig. 1A, panels a1-c1), whereas the protein expression of NCAPG was at a high level in 60/88 (68.2\%) of the HCC tissues (Fig. 1A, panels a2-c2). Therefore, NCAPG protein was overexpressed in the HCC tissues compared to the paired normal hepatocellular tissues $(\mathrm{P}<0.001)$.

Association between NCAPG protein expression and clinicopathological characteristics in patients with $H C C$. The data on the association of NCAPG overexpression with the clinicopathological characteristics of the patients with HCC are shown in Table I. The protein expression of NCAPG in the tumor tissues was strongly associated with the recurrence $(\mathrm{P}=0.031)$, the time of recurrence $(\mathrm{P}=0.006)$, metastasis $(\mathrm{P}=0.020)$, differentiation $(\mathrm{P}=0.021)$ and $\mathrm{TNM}$ stage $(\mathrm{P}=0.036)$. Kaplan-Meier curves were plotted to stratify NCAPG expression for the overall survival of the patients with HCC. Our data indicated that NCAPG overexpression was associated with a poor overall survival of these patients (Fig. $1 \mathrm{~B}, \mathrm{P}<0.05$ ).

Detection of NCAPG protein in different cell lines. The results of western blot analysis revealed that the MHCC-LM3 and Hu7 cell lines had a higher protein expression of NCAPG among these cell lines, which were selected for subsequent functional assays (Fig. 2A).

siRNA-mediated knockdown of NCAPG inhibits NCAPG protein levels and the proliferation of $2 \mathrm{HCC}$ cell lines. NCAPG siRNA was used to transfect the $2 \mathrm{HCC}$ cell lines. After $48 \mathrm{~h}$ of transfection, the protein expression level of NCAPG was downregulated, as shown by western blot analysis. It was shown that the NCAPG_s1, NCAPG_s2 siRNA sequences were the most effective (Fig. 2B). In order to better understand the effects of NCAPG knockdown on cell viability, CCK-8 assay was employed. The results revealed that the silencing of NCAPG expression induced a marked reduction in the viability of the 2 cell lines compared with the control groups (Fig. $2 \mathrm{C}, \mathrm{P}<0.05$ ). These results demonstrate that NCAPG suppression inhibits the proliferative ability of the HCC cells.

Depletion of NCAPG affects the cell cycle distribution in the $2 \mathrm{HCC}$ cell lines. Flow cytometry was employed to examine the effects of NCAPG siRNA on the cell cycle of HCC cells. The 
A

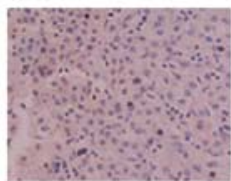

a1

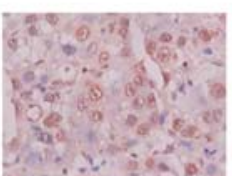

a2

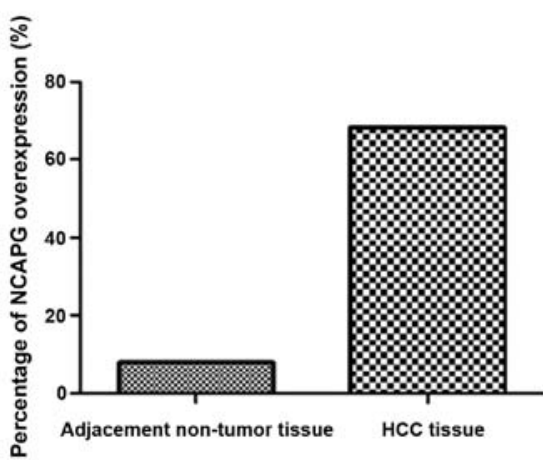

$\mathrm{B}$

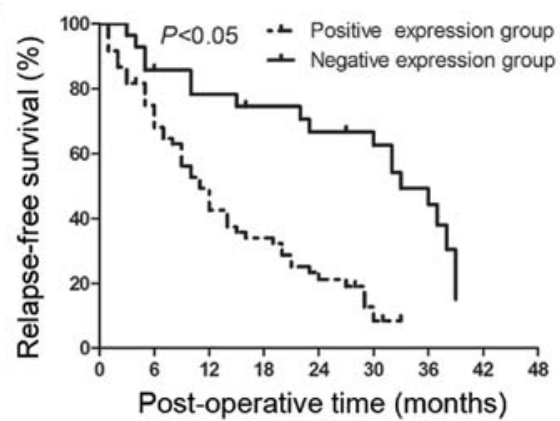

Figure 1. NCAPG overexpression in HCC tissues and its association with the survival of patients with HCC. (A) Immunohistochemical staining of NCAPG protein in HCC tissues. NCAPG protein was localized in the tumor cell nuclei (panels a2-c2). The first row of images (panels a1-c1) were selected from the 81/88 unstained paracancerous tissue specimens as the representative of a low NCAPG protein expression level, while the second row of images (panels a2-c2) are the corresponding HCC tissues from the 60/88 stained HCC tissues as the representative of the overexpression of NCAPG. (B) Kaplan-Meier curves stratified by NCAPG expression levels in HCC This was used to investigate the correlation between NCAPG expression and relapse-free survival time of patients with HCC. A positive NCAPG expression was associated with a poor prognosis. NCAPG, non-SMC condensin I complex subunit G; HCC, hepatocellular carcinoma.

percentage of cells in the G1 phase and G2 phase was lower in the NCAPG siRNA-transfected cells than in the negative siRNA control groups (Fig. 3A, $\mathrm{P}<0.001$ ). Additionally, the percentage of cells in the S phase was higher in the NCAPG siRNA-transfected cells compared with the negative siRNA control cells (Fig. 3A, P<0.001). Additionally, the levels of cyclin A1 and CDK2 were reduced in the NCAPG siRNA-transfected cells (Fig. 3B).

Depletion of NCAPG induces the apoptosis of the 2 HCC cell lines. To determine whether NCAPG affects the apoptosis of HCC cells, we investigated the apoptotic rate of the treated
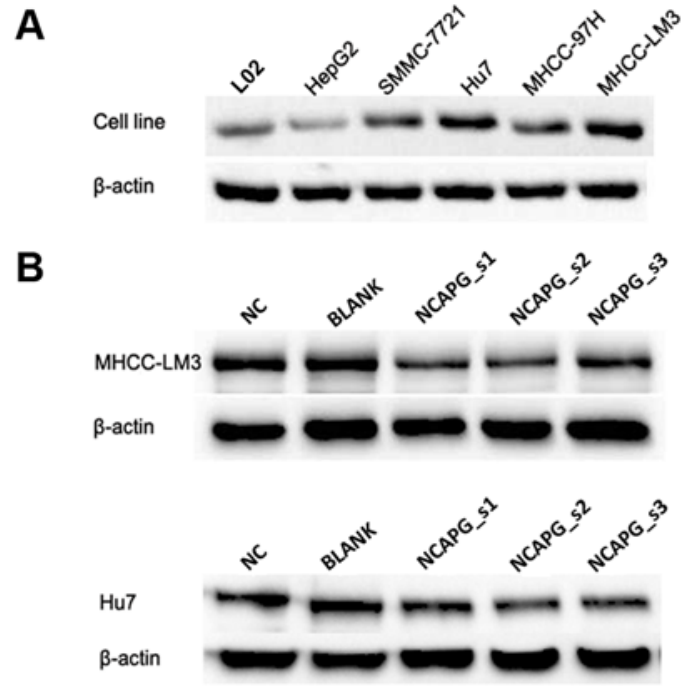

C

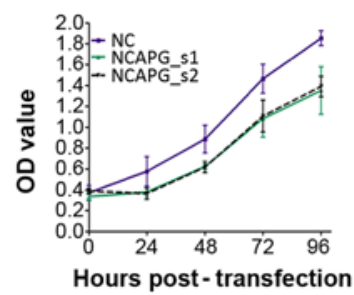

MHCC-LM3

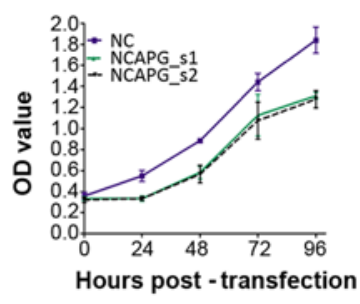

Hu7
Figure 2. Effects of reduced NCAPG expression on the inhibition of HCC cell viability. (A) Western blot showing different NCAPG protein expressions in L02 normal cell line and different HCC cell lines. (B) Three different siRNA constructs were transiently transfected into HCC cells to knock down NCAPG expression. Western blot showing that the expression level of NCAPG was downregulated after $48 \mathrm{~h}$ of transfection. (C) Effects of NCAPG siRNAs on the proliferation of MHCC-LM3 and Hu7 cells over a 96-h period by CCK-8 assay. Results showing that the silencing of NCAPG expression caused a marked reduction in the viability of MHCC-LM3 and Hu7 cell lines compared with the negative control (NC) groups. NCAPG, non-SMC condensin I complex subunit G; HCC, hepatocellular carcinoma.

HCC cells by flow cytometry. The results revealed that the apoptotic rates of the cells in the NCAPG siRNA-transfected group were markedly higher than those in the negative siRNA control groups (Fig. 4A, $\mathrm{P}<0.001$ ). This suggested that the silencing of NCAPG induced the apoptosis of HCC cells. Subsequently, the expression level of cell apoptosis-associated proteins indicated abnormal alternations in the NCAPG siRNAtransfected groups, including the increased expression of Bax and caspase-3, and the decreased expression of Bcl-2 (Fig. 4B). These results indicated that the alterations in cell apoptosis may be related to apoptosis-associated proteins by the downregulation of NCAPG.

NCAPG silencing inhibits the migration and invasion of the 2 HCC cell lines. The effects of NCAPG knockdown on the migratory and invasive activity of human $\mathrm{HCC}$ cells were reflected by Transwell assay. Compared with the negative siRNA control groups, the cells transfected with NCAPG siRNA exhibited weaker migratory and invasive abilities (Fig. 5A and B, P<0.001). To further explore the influence of NCAPG, we analyzed metastasis-related proteins, such as E- and N-cadherin and HOXB9, by western blot analysis. The results revealed that the expres- 
Table I. Associatoin between NCAPG protein expression and clinicopathological characeristics of patients with HCC.

\begin{tabular}{|c|c|c|c|c|c|}
\hline Characteristics & $\begin{array}{l}\text { No. of } \\
\text { patients }\end{array}$ & $\begin{array}{c}\text { NCAPG-positive } \\
\mathrm{n}(\%)\end{array}$ & $\begin{array}{c}\text { NCAPG-negative } \\
\mathrm{n}(\%)\end{array}$ & $\chi^{2}$ & P-value \\
\hline \multicolumn{6}{|l|}{ Sex } \\
\hline Male & 75 & $51(68.0)$ & $24(32.0)$ & \multirow[t]{2}{*}{0.008} & \multirow[t]{2}{*}{1.000} \\
\hline Female & 13 & $9(69.2)$ & $4(30.8)$ & & \\
\hline \multicolumn{6}{|l|}{ Age (years) } \\
\hline$<60$ & 77 & $53(68.8)$ & $24(31.2)$ & \multirow[t]{2}{*}{0.120} & \multirow[t]{2}{*}{0.738} \\
\hline$\geq 60$ & 11 & $7(63.6)$ & $4(36.4)$ & & \\
\hline \multicolumn{6}{|l|}{ Hepatitis B } \\
\hline Positive & 80 & $54(67.5)$ & $26(32.5)$ & \multirow[t]{2}{*}{0.189} & \multirow[t]{2}{*}{1.000} \\
\hline Negative & 8 & $6(75.0)$ & $2(25.0)$ & & \\
\hline \multicolumn{6}{|l|}{$\operatorname{AFP}(\mu \mathrm{g} / \mathrm{l})$} \\
\hline$<400$ & 58 & $38(65.5)$ & $20(34.5)$ & \multirow[t]{2}{*}{0.557} & \multirow[t]{2}{*}{0.630} \\
\hline$\geq 400$ & 30 & $22(73.3)$ & $8(26.7)$ & & \\
\hline \multicolumn{6}{|l|}{ Cirrhosis } \\
\hline Yes & 59 & $37(62.7)$ & $22(37.3)$ & \multirow[t]{2}{*}{2.469} & \multirow[t]{2}{*}{0.147} \\
\hline No & 29 & $23(79.3)$ & $6(20.7)$ & & \\
\hline \multicolumn{6}{|l|}{ Tumor size $(\mathrm{cm})$} \\
\hline$\leq 3.0$ & 14 & $9(64.3)$ & $5(35.7)$ & \multirow[t]{2}{*}{0.116} & \multirow[t]{2}{*}{0.760} \\
\hline$>3.0$ & 74 & $51(68.9)$ & $23(31.1)$ & & \\
\hline \multicolumn{6}{|l|}{ No. of tumors } \\
\hline 1 & 67 & $43(64.2)$ & $24(35.8)$ & \multirow[t]{2}{*}{2.073} & \multirow[t]{2}{*}{0.186} \\
\hline$>1$ & 21 & $17(81.0)$ & $4(19.0)$ & & \\
\hline \multicolumn{6}{|l|}{ Tumor capsule } \\
\hline Yes & 38 & $24(63.2)$ & $14(36.8)$ & \multirow[t]{2}{*}{0.778} & 0.489 \\
\hline No & 50 & $36(72.0)$ & $14(28.0)$ & & \\
\hline Differentiation & & & & & \\
\hline Well & 22 & $10(45.5)$ & $12(54.5)$ & 7.748 & 0.021 \\
\hline Moderate & 43 & $31(72.1)$ & $12(27.9)$ & & \\
\hline Poor & 23 & $19(82.6)$ & $4(17.4)$ & & \\
\hline TNM stage & & & & & \\
\hline $\mathrm{I}+\mathrm{II}$ & 65 & $40(61.5)$ & $25(38.5)$ & 5.059 & 0.036 \\
\hline III+IV & 23 & $20(87.0)$ & $3(13.0)$ & & \\
\hline BCLC stage & & & & & \\
\hline A & 59 & $36(61.0)$ & $23(39.0)$ & 4.346 & 0.114 \\
\hline B & 14 & $12(85.7)$ & $2(14.3)$ & & \\
\hline $\mathrm{C}$ & 15 & $12(80.0)$ & $3(20.0)$ & & \\
\hline Metastasis $^{\mathrm{a}}$ & & & & & \\
\hline Yes & 39 & $32(82.1)$ & $7(17.9)$ & 6.211 & 0.020 \\
\hline No & 49 & $28(57.1)$ & $21(42.9)$ & & \\
\hline Recurrence & & & & & \\
\hline Yes & 67 & $50(74.6)$ & $17(25.4)$ & 5.376 & 0.031 \\
\hline No & 21 & $10(47.6)$ & $11(52.4)$ & & \\
\hline $\begin{array}{l}\text { Recurrence time } \\
\text { (months) }\end{array}$ & & & & & \\
\hline$<6$ & 36 & $30(83.3)$ & $6(16.7)$ & 10.319 & 0.006 \\
\hline$\geq 6 \leq$ to $<12$ & 8 & $7(87.5)$ & $1(12.5)$ & & \\
\hline$\geq 12$ & 44 & $23(52.3)$ & $21(47.7)$ & & \\
\hline
\end{tabular}

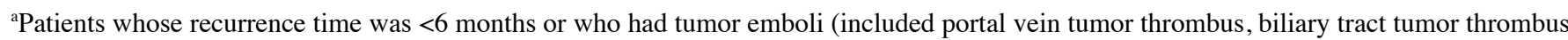
and hepatic vein tumor thrombus) as metastasis. Values in bold font indicate statistical significance. NCAPG, non-SMC condensin I complex subunit G; HCC, hepatocellular carcinoma; AFP, alpha-fetoprotein; BCLC, Barcelona clinic liver cancer. 
A
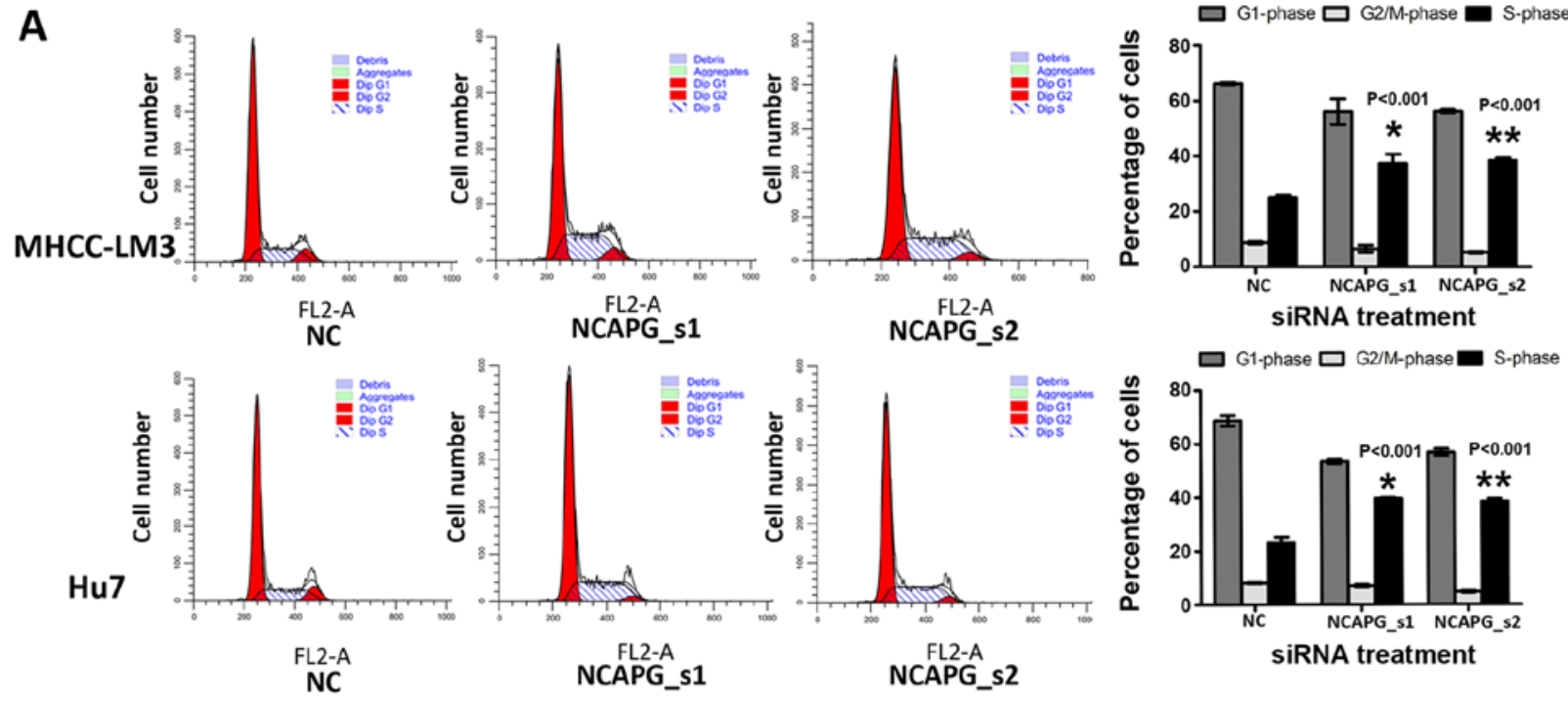

B

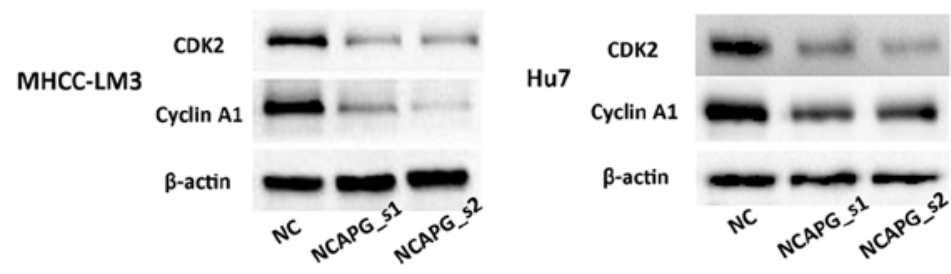

Figure 3. Cell cycle analysis by flow cytometry. Two NCAPG siRNAs were transiently transfected into HCC cells and then subjected to flow cytometric cell cycle analysis and western blot analysis. (A) The depletion of NCAPG inhibited cell cycle progression and caused S phase arrest in MHCC-LM3 and Hu7 cells. (B) Western blot showing that the levels of cyclin A1 and CDK2 were reduced in the NCAPG siRNA-transfected groups compared with the negative control (NC) groups. NCAPG, non-SMC condensin I complex subunit G; HCC, hepatocellular carcinoma.

A

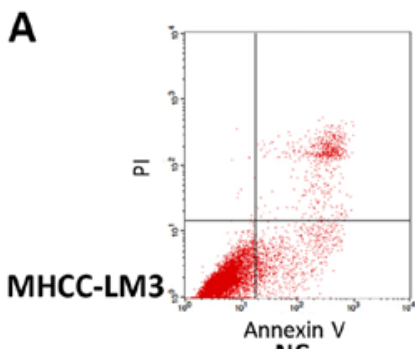

NC

Hu7

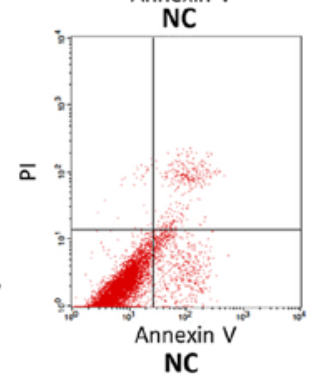

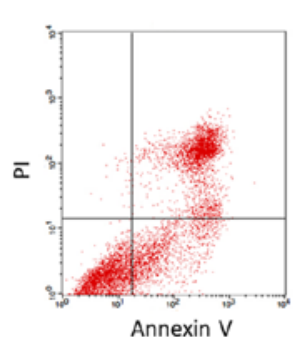

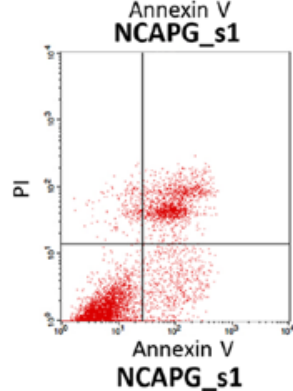

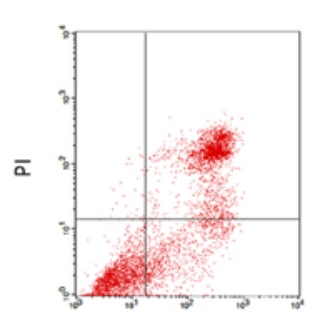

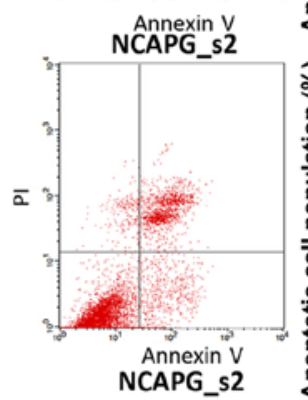

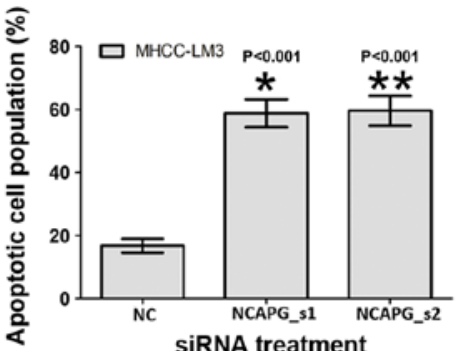

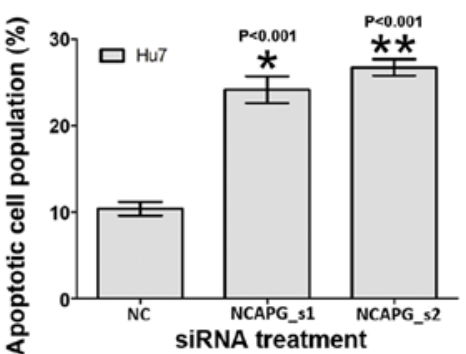

B

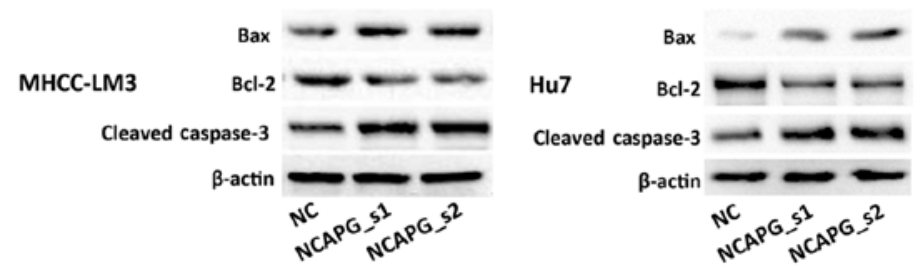

Figure 4. Analysis of apoptosis by flow cytometry. Two NCAPG siRNAs were transiently transfected into HCC cells and the apoptosis of MHCC-LM3 and Hu7 cells was assessed by flow cytometric apoptosis assay. (A) The number of apoptosis NCAPG siRNA-transfected MHCC-LM3 and Hu7 cells was significantly higher than the negative control (NC) groups. (B) Western blot showing that the levels of Bax and cleaved caspase-3 were increased, and the levels of Bcl-2 were reduced in the NCAPG siRNA-transfected groups. NCAPG, non-SMC condensin I complex subunit G; HCC, hepatocellular carcinoma. 
A
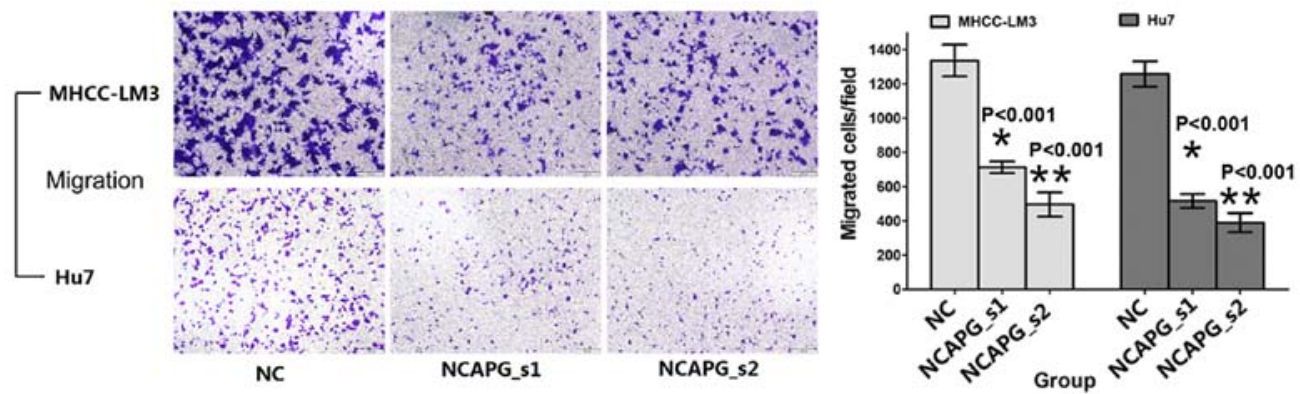

B
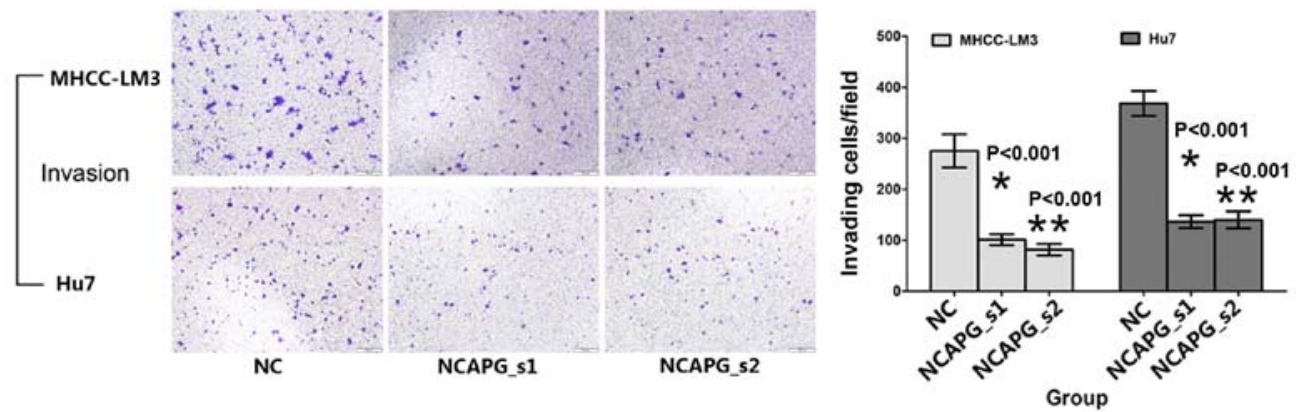

C
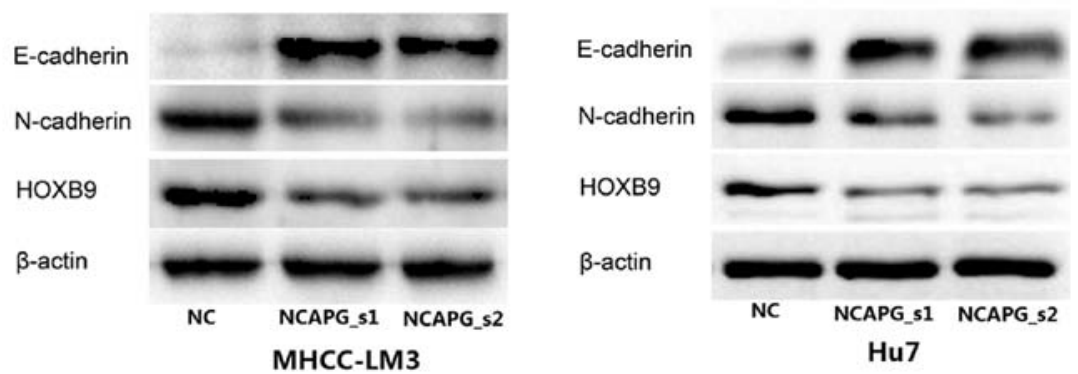

Figure 5. Effects of reduced NCAPG expression on the inhibition of HCC cell migration and invasion. (A) Migration and (B) invasion assays demonstrated that NCAPG siRNA-transfected MHCC-LM3 and Hu7 cells showed reduced migratory and invasion abilities when compared with the negative control (NC) groups. (C) Western blot showing that the levels of E-cadherin were upregulated, and those of N-cadherin and HOXB9 were downregulated upon transfection with NCAPG siRNA. NCAPG, non-SMC condensin I complex subunit G; HCC, hepatocellular carcinoma.

sion of E-cadherin was upregulated, while that of $\mathrm{N}$-cadherin and HOXB9 was downregulated upon transfection with NCAPG siRNA (Fig. 5C). These results indicate that NCAPG plays a critical role in HCC cell migration and invasion.

\section{Discussion}

NCAPG, a component of the condensin complex, is highly associated with the condensation of mitotic chromosomes and the proper segregation of sister chromatid in the division of the nucleus. Currently, several studies on NCAPG have suggested that NCAPG plays the role of a tumor promoter in the development of HCC. Jäger et al (11) investigated the expression of NCAPG in normal and tumor cells and tissue by RT-PCR and northern blot analysis. Their findings showed that NCAPG had the highest expression in the testis, a multifarious expression in tumor cells and a low expression in the thymus, and there was no detectable signal in other normal tissues. As we know, testes and tumor cells have a stronger ability of division and proliferation than other normal tissues. This indicates that a higher expression of NCAPG may promote the ability of division and proliferation of tumor cells. Furthermore, our our data indicated that the depletion of NCAPG led to HCC cell cycle arrest at the $\mathrm{S}$ phase and induced apoptosis. Satow et al (13) found that the NCAPG protein levels in HCC were higher compared with the adjacent non-tumorous liver tissue and that using siRNA-NCAPG to knockdown NCAPG protein expression significantly inhibited the proliferation of HCC cells and the growth rate of HCC xenografts inoculated into nude mice. Our immunohistochemistry statistical results and cell proliferation assays also confirmed this.

At specific phases of the cell cycle, the sequential activation of CDKs can regulate the progression of the mammalian cell division cycle. CDK activities are dependent on the association with cyclins and co-factors, whose levels oscillate throughout the cell cycle (14). Additionally, the activity of CDK2-cyclin A complexes are the key factors for DNA replication. Previous research has indicated that $\mathrm{CDK} 2$-cyclin A complexes can promote DNA replication in vitro (15). Therefore, decreases in CDK2 and cyclin A protein levels can inhibit DNA replication in vivo $(16,17)$ and result in $\mathrm{S}$-phase arrest $(14,18,19)$. In this study, the expression of cell-cycle-associated proteins, including cyclin A1 and CDK2 proteins, was detected by western blot analysis to elucidate the molecular mechanisms of cell cycle distribution changes. Our results revealed that the silencing of NCAPG, compared to the control groups, resulted in a decrease in the percentage of cells in the G1 and G2 phase, an increase in the number of cells in the $\mathrm{S}$ phase by flow cytometry and 
a decrease in cyclin $\mathrm{A} 1$ and $\mathrm{CDK} 2$ protein expression, which indicates that NCAPG may be a cell proliferation promoter in HCC cells. In addition, we demonstrated, by western blot analysis, that apoptosis was induced by transfection with NCAPG siRNA, and there was a corresponding change in the levels of cell apoptosis-associated proteins; NCAPG silencing upregulated Bax and cleaved caspase- 3 and downregulated Bcl-2 expression. This result indicates that NCAPG acts as an anti-apoptotic factor in the cell apoptotic process.

Recurrence and metastasis are the main causes of a poor prognosis of patients with HCC. Therefore, reducing the migratory and invasive abilities of HCC cells can effectively reduce reoccurrence and metastasis and prolong the survival time. HOXB9 has been shown to promote the invasion and metastasis of malignant tumors in previous studies (20-24). Hayashida et al (21) showed that HOXB9 can promote epithelial-mesenchymal transition (EMT) in breast cancer. In the process of EMT, epithelial cells lose polarity and obtain more migratory ability. Yuan et al (22) confirmed that the depletion of HOXB9 significantly inhibited the invasion and metastasis of HCC cells. Conversely, the invasive and metastatic ability was promoted by increasing the expression of HOXB9. Our western blot analysis results revealed that the expression of HOXB9 was downregulated by transfection with NCAPG siRNA in the HCC cells. Additionally, the expression of E-cadherin was upregulated and the expression of $\mathrm{N}$-cadherin was downregulated by transfection with NCAPG siRNA in the HCC cells. Our Transwell assay results demonstrated that the invasive and metastatic ability of the $\mathrm{HCC}$ cell lines was suppressed in vitro. These results indicate that NCAPG may act as a promoter of invasion and metastasis in $\mathrm{HCC}$ by regulating the expression of HOXB9, N- and E-cadherin.

In conclusion, our results suggest that NCAPG expression is associated with the clinicopathological characteristics, cell cycle, apoptosis and cell migration and invasion in human $\mathrm{HCC}$, as an oncogenic protein playing an important role in the occurrence and development of primary liver cancer. Therefore, NCAPG may be a potential target for the diagnosis and therapy of patients with HCC.

\section{Acknowledgements}

The present study was supported in part by a grant from the Second Affiliated Hospital of Nanchang University (no. 2016YNQN12004) and the Natural Science Foundation of Jiangxi Province, China (no. 20151BAB205101).

\section{References}

1. Torre LA, Bray F, Siegel RL, Ferlay J, Lortet-Tieulent J and Jemal A: Global cancer statistics, 2012. CA Cancer J Clin 65: 87-108, 2015.

2. Giordano S and Columbano A: Met as a therapeutic target in HCC: Facts and hopes. J Hepatol 60: 442-452, 2014.

3. Hirano T, Kobayashi R and Hirano M: Condensins, chromosome condensation protein complexes containing XCAP-C, XCAP-E and a Xenopus homolog of the Drosophila Barren protein. Cell 89: 511-521, 1997.

4. Gerlich D, Hirota T, Koch B, Peters JM, Ellenberg J and Condensin I: Condensin I stabilizes chromosomes mechanically through a dynamic interaction in live cells. Curr Biol 16: 333-344, 2006.
5. Kimura K, Cuvier O and Hirano T: Chromosome condensation by a human condensin complex in Xenopus egg extracts. J Biol Chem 276: 5417-5420, 2001.

6. Herzog S, Nagarkar Jaiswal S, Urban E, Riemer A, Fischer S and Heidmann SK: Functional dissection of the Drosophila melanogaster condensin subunit Cap-G reveals its exclusive association with condensin I. PLoS Genet 9: e1003463, 2013.

7. Seipold S, Priller FC, Goldsmith P, Harris WA, Baier H and Abdelilah-Seyfried S: Non-SMC condensin I complex proteins control chromosome segregation and survival of proliferating cells in the zebrafish neural retina. BMC Dev Biol 9: 40, 2009.

8. Hirano T: At the heart of the chromosome: SMC proteins in action. Nat Rev Mol Cell Biol 7: 311-322, 2006.

9. Hirano T: Condensins: Organizing and segregating the genome. Curr Biol 15: R265-R275, 2005.

10. Eberlein A, Takasuga A, Setoguchi K, Pfuhl R, Flisikowski K, Fries R, Klopp N, Fürbass R, Weikard R and Kühn C: Dissection of genetic factors modulating fetal growth in cattle indicates a substantial role of the non-SMC condensin I complex, subunit G (NCAPG) gene. Genetics 183: 951-964, 2009.

11. Jäger D, Stockert E, Jäger E, Güre AO, Scanlan MJ, Knuth A, Old LJ and Chen YT: Serological cloning of a melanocyte rab guanosine 5'-triphosphate-binding protein and a chromosome condensation protein from a melanoma complementary DNA library. Cancer Res 60: 3584-3591, 2000.

12. Lam WW, Peterson EA, Yeung M and Lavoie BD: Condensin is required for chromosome arm cohesion during mitosis. Genes Dev 20: 2973-2984, 2006.

13. Satow R, Shitashige M, Kanai Y, Takeshita F, Ojima H, Jigami T, Honda K, Kosuge T, Ochiya T, Hirohashi S, et al: Combined functional genome survey of therapeutic targets for hepatocellular carcinoma. Clin Cancer Res 16: 2518-2528, 2010.

14. Wheeler LW, Lents NH and Baldassare JJ: Cyclin A-CDK activity during G1 phase impairs MCM chromatin loading and inhibits DNA synthesis in mammalian cells. Cell Cycle 7: 2179-2188, 2008.

15. Fotedar A, Cannella D, Fitzgerald P, Rousselle T, Gupta S, Dorée $\mathrm{M}$ and Fotedar R: Role for cyclin A-dependent kinase in DNA replication in human S phase cell extracts. J Biol Chem 271: 31627-31637, 1996.

16. Ogryzko VV, Wong $P$ and Howard BH: WAF1 retards S-phase progression primarily by inhibition of cyclin-dependent kinases. Mol Cell Biol 17: 4877-4882, 1997.

17. Ishimi Y,Komamura-Kohno Y, You Z, Omori A and Kitagawa M: Inhibition of Mcm4,6,7 helicase activity by phosphorylation with cyclin A/Cdk2. J Biol Chem 275: 16235-16241, 2000.

18. Song X, Li L, Shi Q, Lehmler HJ, Fu J, Su C, Xia X, Song E and Song Y: Polychlorinated biphenyl quinone metabolite promotes p53-dependent DNA damage checkpoint activation, S Phase cycle arrest and extrinsic apoptosis in human liver hepatocellular carcinoma HepG2 cells. Chem Res Toxicol 28: 2160-2169, 2015.

19. Sever-Chroneos Z, Angus SP, Fribourg AF, Wan H, Todorov I, Knudsen KE and Knudsen ES: Retinoblastoma tumor suppressor protein signals through inhibition of cyclin-dependent kinase 2 activity to disrupt PCNA function in S phase. Mol Cell Biol 21: 4032-4045, 2001.

20. Nguyen DX, Chiang AC, Zhang XH, Kim JY, Kris MG, Ladanyi M, Gerald WL and Massagué J: WNT/TCF signaling through LEF1 and HOXB9 mediates lung adenocarcinoma metastasis. Cell 138: 51-62, 2009.

21. Hayashida T, Takahashi F, Chiba N, Brachtel E, Takahashi M, Godin-Heymann N, Gross KW, Vivanco M, Wijendran V, Shioda T, et al: HOXB9, a gene overexpressed in breast cancer, promotes tumorigenicity and lung metastasis. Proc Natl Acad Sci USA 107: 1100-1105, 2010.

22. Yuan R, Wang K, Hu J, Yan C, Li M, Yu X, Liu X, Lei J, Guo W, Wu L, et al: Ubiquitin-like protein FAT10 promotes the invasion and metastasis of hepatocellular carcinoma by modifying $\beta$-catenin degradation. Cancer Res 74: 5287-5300, 2014.

23. Chiba N, Comaills V, Shiotani B, Takahashi F, Shimada T, Tajima K, Winokur D, Hayashida T, Willers H, Brachtel E, et al: Homeobox B9 induces epithelial-to-mesenchymal transition-associated radioresistance by accelerating DNA damage responses. Proc Natl Acad Sci USA 109: 2760-2765, 2012.

24. Sha L, Dong L, Lv L, Bai L and Ji X: HOXB9 promotes epithelial-to-mesenchymal transition via transforming growth factor- $\beta 1$ pathway in hepatocellular carcinoma cells. Clin Exp Med 15: 55-64, 2015. 